\title{
Physiological Status of Stunned and Non-Stunned Broilers: Blood Profile, and Brain Histopathology
}

\section{Aryani Sismin Satyaningtijas ${ }^{1 *}$, Niken Ulupi ${ }^{2}$, Yulvian Sani ${ }^{3}$, Koekoeh Santoso', Elok Budi Retnani ${ }^{4}$, Hera Maheshwari', Desrayni Hanadhita', Jefri Naldi', Irwan Oktoni', David Anwar ${ }^{2}$, Ainul Khadija Saleema ${ }^{2}$}

\author{
'Departement of Anatomy, Physiology, and Pharmacology, Faculty of Veterinary Medicine, IPB \\ University, Bogor, Indonesia \\ ${ }^{2}$ Departement of Animal Production Technology, Faculty of Animal Husbandry, IPB University, Bogor, \\ Indonesia \\ ${ }^{3}$ Bogor Research Center for Veterinary Science, Bogor \\ dDepartement of Animal Disease and Veterinary Public Health, Faculty of Veterinary Medicine, IPB \\ University, Bogor, Indonesia \\ *Corresponding author: Aryani Sismin Satyaningtyas (niekesis@yahoo.co.id)
}

\begin{abstract}
Stunning method before slaughtering is considered more animal welfare compared to a non-stunning method and also reduces stress levels in broilers. As for the bleed-out efficiency, testing was done indirectly by blood volume measurement which consists of erythrocyte count, leucocyte count, hemoglobin levels, hematocrit values, and erythrocyte index in broilers. Brain histopathology was also carried out to see the effect of electrical stunning towards the brain tissues. The stunning method used is electrical stunning via water bath with the capacity of $146 \mathrm{~mA}$. The results showed that the stunning method before slaughtering caused smaller number of erythrocytes and hematocrit values, and the brain histopathology showed that stunning causes encephalopathy
\end{abstract}

Keywords: broilers, encephalopathy, slaughter, stunning.

Copyright $\odot 2020$ JRVI. All rights reserved.

\section{Introduction}

The process of slaughtering livestock is an essential part of producing safe, healthy, pure and halal consumption meat. According to OIE (2008), there are two methods of slaughtering, namely slaughtering which is preceded by stunning and non-stunning. The most common slaughter done in modern poultry slaughterhouses, especially in developed countries, is stunning before slaughter. Both of these methods can affect the condition of livestock that will be slaughtered. Stressful conditions can result in changes in the circulation or the tissues. Changes in circulation can be observed by the blood profile, whereas changes in tissue can be detected by brain histopathology.

Materials and Methods

Resting and Fasting of Broilers 
A total of 20 broilers obtained from the farm were then rested and fasted for 18 hours before being slaughtered. The purpose of resting is to reduce stress, while fasting is for hygiene and sanitary purpose during evisceration.

\section{Blood Sampling}

Blood samples were taken twice. First, an hour before the chickens were slaughtered as the initial condition. One $\mathrm{ml}$ of blood were drawn from the brachial vein using a syringe. Second, blood sampling was carried out after the broilers were slaughtered by collecting $1 \mathrm{ml}$ blood from the neck. The collected blood samples were then stored in a vacuum tube with EDTA anticoagulants and rotated in the form of number 8 to mix. The blood-filled vacuum tube was placed in a cooling box.

\section{Stunning}

The stunning method used was electrical stunning via a water bath. This method uses water as a medium to supply electricity to the chicken's head. The electric current used was $0.146 \mathrm{~A}$ for 5 seconds. Electrodes were attached to the chicken's feet, and the chickens were hung upside down. Their heads were quickly dipped in a tub of water that has been electrified for 5 seconds. The chickens were immediately slaughtered after they lose consciousness.

\section{Erythrocyte Count}

The method of calculating the number of erythrocytes refers to Gandasoebrata (2007). The blood was aspirated to the 0.5 marks of the erythrocyte pipette then excess blood at the end of the pipette was wiped followed by Rees \& Ecker's solution aspiration up to mark 101. The erythrocyte pipette was then closed at the base and the tip with a finger and then homogenized by moving the pipette resembling number 8 . The solution that has been homogeneous was then discarded a little, about 3 to 5 drops. Hemocytometer with a cover glass was placed on the table and filled with the solution. The solution in the hemocytometer was allowed to stand for a few minutes so that the precipitation is ideal. The hemocytometer was then placed on a microscope table. Erythrocyte counting was carried out by viewing the erythrocyte under $400 x$ magnification using a counting chamber.

Calculation of the number of erythrocytes seen in the five red squares is then summed and expressed as $n$. The value of $n$ is multiplied by the factor of dilution and volume of the calculated chamber. The dilution factor is $1 / 100$, and the calculated chamber volume is $5 \times$ $1 / 250$. The total erythrocytes can merely be calculated with $\mathrm{n}$ values multiplied by 5000 ( $\Sigma$ SDM $=\mathrm{n} \times 5000)$. The number of erythrocytes in the blood is expressed in units of millions of cells/ $\mu$ l.

\section{Hematocrit Value Calculation}

The method of calculating hematocrit values refers to Gandasoebrata (2007). Chicken blood was aspirated into the capillary tube by tilting the capillary tube then the index finger opens and closes the tip of the tube until the blood almost fill the tubes (leaving about $1 \mathrm{~cm}$ empty). The capillary tube was then clogged at the end of the tube with a special plug. The capillary tube was then centrifuged with a centrifuge at the speed of $10,000 \mathrm{rpm}$ for 4-5 minutes or at the speed of $16,000 \mathrm{rpm}$ for 2 minutes. The results of the centrifugation were then read with the help of a microhematocrit reader. 


\section{Hemoglobin Level Calculation}

The method of estimating hemoglobin levels refers to Gandasoebrata (2007). Calculation of hemoglobin levels in this study uses the Sahli method. Blood of the broilers was aspirated into the hemoglobin pipette up to mark 20. Blood was then transferred into the Sahli tube which was previously filled with $0.1 \mathrm{~N} \mathrm{HCl}$ as much as the lowest boundary line of the tube. Blood mixture and $0.1 \mathrm{~N} \mathrm{HCl}$ were homogenized by drawing in and blowing out contents of the pipette slowly. Distilled water was added drop by drop into the Sahli tube while stirring it slowly. Addition of the distilled water was stopped once the color of the mixture is the same as the color of the standard solution. Blood hemoglobin levels read were carried out by looking at the fluid meniscus in the Sahli tube.

\section{Erythrocyte Index Calculation}

Erythrocyte index was used to determine the type of anemia based on erythrocyte morphology. The calculated index was Mean Corpuscular Volume (MCV), Mean Corpuscular Hemoglobin $(\mathrm{MCH})$, and Mean Corpuscular Hemoglobin Concentration (MCHC).

\section{Blood Volume Measurement}

After the chickens were slaughtered, they were hung by the head until the bleeding stops in 1 minute. The blood that came out was immediately collected into a measuring cylinder, and the volume was recorded.

\section{Brain Sample}

Broilers were slaughtered and then necropsied. The time taken from slaughtering to organ harvesting was 1 hour. Brain were taken through a necropsy. The brain sample was inserted into a plastic bag filled with BNF $10 \%$ and was then sent to the laboratory for histopathology testing.

\section{Results and Discussions}

\section{Blood Volume Measurements}

Direct and quantitative testing of bleeding efficiency was tested by measuring the volume of bleeding of chickens when slaughtered. The bleeding volume in stunned and non-stunned chickens can be seen in Table 1. Data from this study showed blood that came out of slaughtered chickens with stunning and non-stunning respectively $1.41 \%$ and $2.25 \%$.

Table 1 The bleeding volume in stunned and non-stunned chicken.

\begin{tabular}{lccc}
\hline Treatment & Weight $(\mathrm{kg})$ & Bleeding volume $(\mathrm{mL})$ & Percentage of bleeding (\%) \\
\hline Stunning & $1.48 \pm 0.11$ & $21.00 \pm 7.73$ & $1.41 \pm 0.52$ \\
Non- & & & \\
stunning & $1.45 \pm 0.06$ & $29.30 \pm 10.60$ & $2.25 \pm 0.68$ \\
\hline
\end{tabular}




\section{Leucocyte}

Data of the number of leukocytes from chickens slaughtered with stunning and non-stunning can be seen in Table 2. The result of this study indicates that chickens stunning before slaughter have normal leukocyte value. In chickens that were given stunning treatment, there was a decrease in the number of leukocytes.

Table 2. Total leukocyte counts before and after slaughter.

\begin{tabular}{lccc}
\hline & & \multicolumn{3}{c}{ Leucocyte } \\
\cline { 2 - 4 } Treatment & 1 hour before slaughter & During slaughter $\left(10^{3} \mathrm{~mm}^{-3}\right)$ & Normal" \\
& $\left(10^{3} \mathrm{~mm}^{-3}\right)$ & $9.33 \pm 3.33$ & $11-13$ \\
\hline Stunning & $12.58 \pm 4.27$ & $11.96 \pm 4.22$ & $11-13$ \\
Non-stunning & $11.10 \pm 3.74$ & & \\
\hline "Orawan and Aengwanich (2007) & &
\end{tabular}

\section{Erythrocyte Profile}

The number of erythrocytes, hemoglobin levels, hematocrit values, and blood erythrocyte index of broilers treated with stunning and non-stunning can be seen in Table 3. The number of erythrocytes of slaughtered chickens with the stunning method is lower than the number of erythrocytes of the non-stunning method. However, the number of erythrocytes was still in the normal range.

Table 3 .Average results of calculation of erythrocyte count, hemoglobin level, and hematocrit value, and blood erythrocyte index.

\begin{tabular}{|c|c|c|c|c|}
\hline \multirow{2}{*}{ Blood Parameter } & \multirow{2}{*}{ Pre Slaughter } & \multicolumn{2}{|c|}{ Post Slaughter } & \multirow{2}{*}{ Normal" } \\
\hline & & Non-Stunning & Stunning & \\
\hline $\begin{array}{l}\text { Erythrocyte } \\
\text { (million/ } \mu \mathrm{l} \text { ) }\end{array}$ & $2.93 \pm 0.30$ & $2.76 \pm 0.49$ & $2.39 \pm 0.40$ & $2.5-3.5$ \\
\hline $\begin{array}{l}\text { Leucocyte }\left(10^{3} \mathrm{~mm}^{-}\right. \\
\left.{ }^{3}\right)\end{array}$ & & $11.96 \pm 4.22$ & $9.33 \pm 3.33$ & $11-13$ \\
\hline Hemoglobin (g\%) & $11.1 \pm 0.70$ & $9.22 \pm 1.48$ & $9.98 \pm 1.51$ & $7-13$ \\
\hline Hematocrit (\%) & $26.28 \pm 1.79$ & $23.93 \pm 3.91$ & $23.13 \pm 3.66$ & $22-35$ \\
\hline$M C V(f l)$ & $90.73 \pm 10.72$ & $88.07 \pm 17.01$ & $98.08 \pm 14.21$ & $90-140$ \\
\hline $\mathrm{MCH}(\mathrm{pg})$ & $38.72 \pm 6.18$ & $33.71 \pm 4.53$ & $42.10 \pm 3.30$ & $33-47$ \\
\hline MCHC (g/dl) & $42.52 \pm 2.61$ & $38.78 \pm 4.25$ & $43.58 \pm 6.10$ & $26-35$ \\
\hline
\end{tabular}

*Adamu et al., (2013)

\section{Brain Histopathology Overview}

From 3 stunned and 3 non-stunned chickens, 4 brain histopathology slides were made for each chicken. Chicken that was stunned showed same encephalopathy characteristic which mainly consists of a thickening of arterioles wall, brain tissues necrosis, neuron, vacuolization and 
congestion (Figure 1). Non-stunned chicken's cerebrum and cerebellum showed no specific abnormalities. Vacuolization occurs allegedly due to the fixation process (Figure 2).
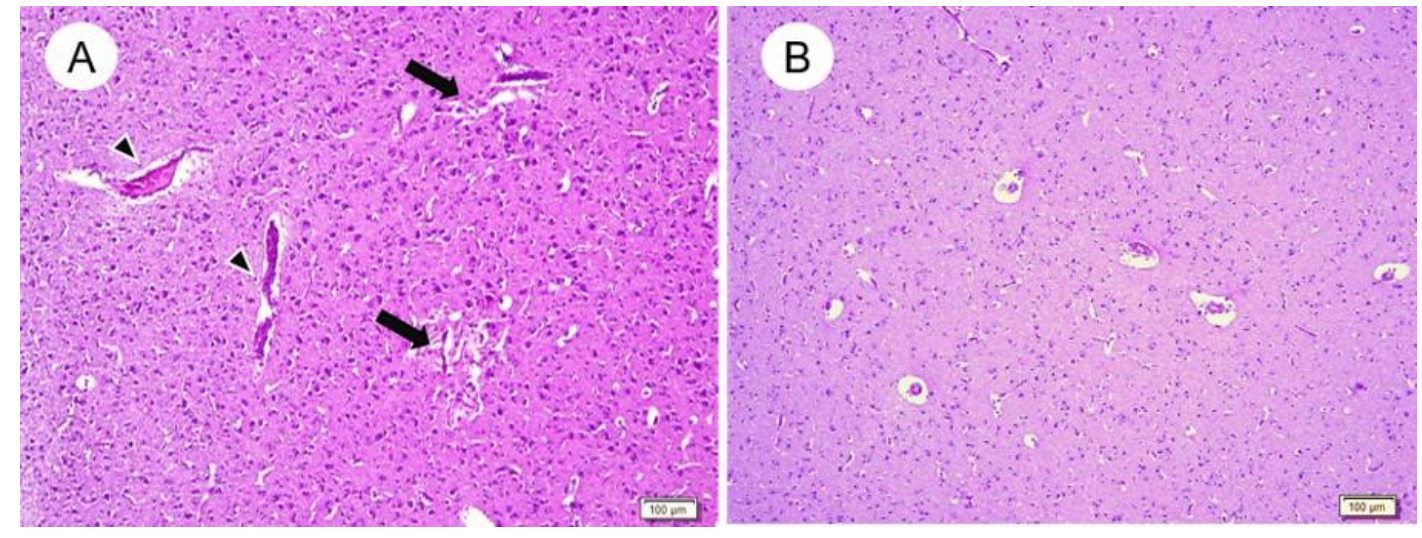

Figure 1. Comparison of the stunned and the non-stunned brain. A. Stunned brain experiences encephalopathy which is characterized by congestion (arrowhead) and many necrosis lesions (arrow).

B. Non-stunned brain showed no specific abnormalities. Hematoxylin-Eosin stain.
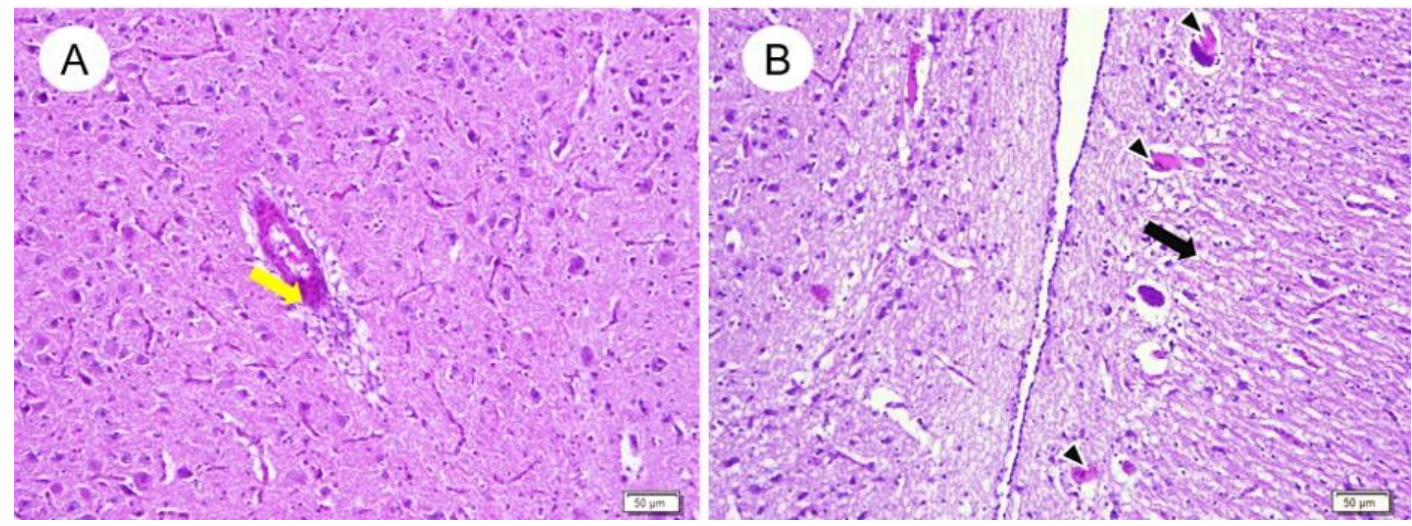

Figure 2. Encephalopathy lesion in the stunned brain. A. Stunned brain artery was thickened and followed by arterial necrosis (yellow arrow). B. Many congestions (arrowhead) and necrosis foci (black arrow) were found in the stunned brain. Hematoxylin-Eosin stain.

\section{Discussion}

\section{Blood Volume Measurement}

Shaw et al. (2009), reported that the total blood in the body of chickens is $6 \%-10 \%$ of the total weight of the chicken. Mohamed and Mohamed (2012) reported that the blood that comes out during slaughter is about $30 \%-50 \%$ of the total blood in the body, in other words, the blood that comes out during slaughter is about $2.1 \%$ of the total body weight. The volume of bleeding of the stunned chickens in this study is far below the average blood volume. Therefore, the possibility of chickens being slaughtered with stunning has lower meat quality because of the high blood volume in meat causes the meat to rot quickly (Aghwan et al., 2016). 


\section{Leucocyte}

When chickens were stunned, respiration decreases and heart pressure weakens and causes oxygen supply to decrease. Oxygen deprivation according to (Hall, 2016), can inhibit leukocyte formation in the body because the leukocyte component formation requires oxygen. Also, the stunning process causes the broilers body to experience stress and vasoconstriction, namely narrowing of the blood vessels (Sabow et al., 2017), which is thought to cause circulation of leukocytes in the blood to be blocked.

\section{Erythrocyte Profile}

In general, the blood profile in the form of erythrocyte counts, hemoglobin levels, and hematocrit values decreased in post slaughter when compared with pre-slaughter. According to Adamu et al. (2013) the number of normal poultry erythrocytes is 2.5-3.5 (million/ $\mu \mathrm{l}$ ). According to (Sabow et al., 2017), the stunning process using electricity causes stress in the chicken's body and can cause vasoconstriction so that it is thought to cause the rate of blood circulation to decrease. A decrease in the blood circulation rate can result in the volume of blood coming out of the chickens that are stunned below the average blood volume (Anwar, 2018). The impact of the decrease in the circulation rate and blood volume causes the number of erythrocytes to decrease.

Pre-slaughter hemoglobin level was higher compared to the post-slaughter hemoglobin level. Hemoglobin levels of chickens slaughtered by the stunning method are higher than the hemoglobin levels of the non-stunning method. However, hemoglobin levels are still in the normal range of 7-13 grams \% (Adamu et al., 2013). Decreased hemoglobin levels are associated with a decrease in the number of erythrocytes. According to Frandson (1993), the number of erythrocytes in the blood correlates positively with hemoglobin levels.

The hematocrit value in pre-slaughter was higher than post-slaughter. Hematocrit value of slaughtered chickens with the stunning method is smaller than the hematocrit value of the nonstunning method. However, the value of chicken hematocrit slaughtered by the stunning and non-stunning method is still in the normal range of 22-35\% (Shittu et al. 2016; Nurwahyuni et al. 2016). The consequences of decreasing hemoglobin levels can affect hematocrit values. According to Stockham and Scott (2008) there is a relationship between hemoglobin levels and hematocrit values. Decreased hematocrit values are also caused by erythrocyte damage, decreased erythrocyte production or are influenced by the number and size of erythrocytes (Coles 1982).

All erythrocyte index values experienced a decline in non-stunning conditions but experienced an increase in stunning conditions when compared to pre-slaughter. $\mathrm{MCV}, \mathrm{MCH}$, and $\mathrm{MCHC}$ values of chickens slaughtered with the stunning method are more magnificent than nonstunning. However, the $\mathrm{MCV}$ and $\mathrm{MCH}$ values are in the normal range in a row, namely 90140 (fL) and 33-47 (pg) (Adamu et al., 2013). MCHC values are above the normal range of 2635 ( $\mathrm{g} / \mathrm{dl}$ ) (Adamu et al., 2013). High hemoglobin levels cause high MCHC values. According to Vimini et al. (1983) respiration of stunned animals decreases and causes the distribution of oxygen to the heart to decrease. Body tissues that lack of oxygen supply cause an increase in erythropoietin production. According to Reece (2015), erythropoietin can improve the process of erythropoiesis, causing an increase in the number of red blood cells. Increased erythropoiesis rate can cause the formation of reticulocyte counts above the normal range. Physiologically, reticulocytes can be found in the blood circulation of around 3\% (Wakenell 2010). The ability of reticulocytes to carry oxygen is not the same as matured red blood cells. The inability to 
carry oxygen can cause anemia. Erythrocyte index in the form of $\mathrm{MCV}, \mathrm{MCH}$, and $\mathrm{MCHC}$ can be used to diagnose anemia. According to Gandasoebrata (2007), anemia is defined based on cell size $(\mathrm{MCV})$ and the amount of hemoglobin per erythrocyte $(\mathrm{MCH}) . \mathrm{MCV}$ values are used to determine the type of macrocytic anemia (above normal limits), normocytic (within normal limits) or microcytic (below normal limits). $\mathrm{MCH}$ value is used to determine the type of anemia, namely hyperchromic anemia (above normal limits), normochromic anemia (within normal limits) or hypochromic anemia (below normal limits).

\section{Brain}

In water bath stunning, chicken's head is required to be fully immersed in an electrical live water bath. The function of stunning is to induce unconsciousness and causes epilepsy in chickens (Raj, 1998). Epilepsy is a neurological disorder as a result of brain damage. It can occur when there is a brain injury, stroke, brain tumor, infections and congenital disabilities (Kwok et al. 2010). Brain damage, encephalopathy as seen in (Figure 1) shows that stunning before slaughter results in thickening of arterioles wall that leads to blood congestion and eventually necrosis of brain tissues due to insufficient supply of oxygen (Figure 2).

\section{References}

Adamu, M., C. Boonkaewwan, N. Gongruttananun, and M. Vongpakorn. 2013. Hematological, Biochemical and Histopathological Changes Caused by Coccidiosis in Chickens. 238-246 pp.

Aghwan, Z. A., A. U. Bello, A. A. Abubakar, J. C. Imlan, and A. Q. Sazili. 2016. Efficient halal bleeding, animal handling, and welfare: A holistic approach for meat quality. Meat Science 121:420-428.

Anwar, D. 2018. Indeks stres ayam broiler yang disembelih dengan cara stunning dan tanpa stunning. IPB University pp.

Frandson, R. D. 1993. Anatomi Dan Fisiologi Ternak. Gadjah Mada University Press, Yogyakarta, 969 pp.

Gandasoebrata, R. 2007. Penuntun Laboratorium Klinik. Dian Rakyat, Jakarta, pp.

Hall, J. E. 2016. Guyton and Hall Textbook of Medical Physiology, 13th ed. Elsevier Saunders, pp.

Kwok, Y., S. J. McPhee, and G. D. Hammer. 2010. Pathophysiology of Disease: An Introduction to Clinical Medicine, 7th ed. McGraw-Hill Medical, New York, pp.

Mohamed, B., and I. Mohamed. 2012. The Effects of Residual Blood of Carcasses on Poultry Technological Quality. Food and Nutrition Sciences 03:1382-1386.

Nurwahyuni, E., E. Sudjarwo, and O. Sjofjan. 2016. Effect of Altitudes on Blood Profiles of the Broilers. Advances in Animal and Veterinary Sciences 4:122-127.

[OIE] Office des International Epizooties. 2008. Slaughter Animals. Accessed on January 11th 2020. http://www.oie.int.

Raj, M. 1998. Welfare during stunning and slaughter of poultry. Poultry Science 77:1815-9.

Reece, W. O. 2015. Duke`s Physiology of Domestic Animals. John Wiley \& Sons, Inc, lowa, pp.

Sabow, A. B., K. Nakyinsige, K. D. Adeyemi, A. Q. Sazili, C. B. Johnson, J. Webster, and M. M. Farouk. 2017. High frequency pre-slaughter electrical stunning in ruminants and poultry for halal meat production: A review. Livestock Science 202:124-134.

Shaw, S., T. Tully, and J. Nevarez. 2009. Avian transfusion medicine.; pp. 334-344 in K. Yagi and M. K. Holowaychuk (eds.), J Compendium, Continuing Education for Veterinarians. vol. 31. John Wiley \& Sons, Inc., Hoboken.

Shittu, M., A. Abiola, O. Ojebiyi, and D. Adejumo. 2016. Gut Morphology and Blood Profile of Finisher Broilers Fed Diets Containing Dried Biscuit Dough Meal. International Journal 
of Livestock Research 6:49.

Stockham, S. L., and M. A. Scott. 2008. Fundamentals of Veterinary Clinical Pathology, 2nd ed. Blackwell Pub, pp.

Vimini, R. J., R. A. Field, M. L. Riley, and T. R. Varnell. 1983. Effect of Delayed Bleeding after Captive Bolt Stunning on Heart Activity and 